\title{
ANNOUNCEMENT \\ An International Conference on the Science and Management of Coastal Dunes
}

\author{
Port Elizabeth and Stellenbosch (Cape Town), South Africa, January 6-11, 1994
}

The aim of the conference is to determine the present state of knowledge of coastal dunes and to formulate strategies for managing them. Specific objectives include the pooling of scientific and management expertise from both hemispheres; determining management strategies necessary to conserve and utilize coastal dunes; and focusing on what needs to be done in order to address the most urgent management needs. Conference topics included in the program will be selected from contributions in Geomorphology, Climatology, Biology, Ecology, Archaeology, Sociology, Policy, Planning, and Management.

The formal program consists of plenary sessions only since the objective is to emphasize the way in which the present states of the art of management and science can be brought together.

The venue for the first 2 days of the conference will be the University of Port Elizabeth, which is situated near the Alexandria dunefield $\left(125 \mathrm{~km}^{2}\right)$. A traveling workshop dealing with management problems associated inter alia with headland bypass dune systems, holiday resorts, groundwater contamination, and the influence of dune management on small estuaries and beaches will occupy the next 2 days. The conference will conclude with 2 days of presentations in Stellenbosch, the heart of the winelands of South Africa and close to Cape Town.

Papers and posters can be submitted for presentation or display at the conference. A panel of internationally recognized referees will be selected by an editorial board to review manuscripts submitted for inclusion in the published proceedings.

Participants interested in attending the conference should reply as soon as possible. The closing date for registration and submission of abstracts is August 1, 1993. Further deadlines for submitting completed manuscripts will be announced.

The language of the conference will be English and all papers must be written and presented in English. No translation facilities will be provided. Authors will be expected to attend the conference and present their papers themselves.

For further information, please contact:

Professor G. C. Bate

Institute for Coastal Research

P.O. Box 1600

Port Elizabeth, South Africa 60000

Telephone: (041) 5042-396

International: + $27415042-396$

Fax: (041) 532317

International: +2741532317 